\title{
Memória e experiência no trabalho do performer: 0 Workcenter de Grotowski e Thomas Richards
}

Martha Ribeiro*

RESUMO: Em visita ao Workcenter de Grotowski e Thomas Richards localizado na cidade de Pontedera na Itália, em junho de 2013, buscamos compreender in loco o treinamento do ator, a partir do legado de Grotowski, no entendimento da Arte como Veículo. Neste artigo, iremos nos deter à seguinte questão: é possível compreender a arte como veículo enquanto um "antídoto", uma saída, para o declínio da experiência, apontado por Benjamim?

Palavras-chave: Jersy Grotowski, Arte como Veículo, performer, experiência

ABSTRACT: Visiting, in June 2013, The Workcenter of Jerzy Grotowski and Thomas Richards, located in Pontedera in Italy, we intend to understand 'in loco' the actor training from the perspective of the legacy of Grotowski, comprehending Art as Vehicle. In this article, we will focus our attention on the following question: is it possible to understand the concept of "art as a vehicle" as an "antidote", a means for escaping from decline of experience, appointed by Benjamin?

Keywords: Jerzy Grotowski, Art as Vehicle, performer, experience

\footnotetext{
* Martha Ribeiro é diretora teatral, professora adjunta no Departamento de Arte e docente no Programa de Pós-Graduação em Estudos Contemporâneos das Artes da Universidade Federal Fluminense. Publicou pela Editora Perspectiva o livro Luigi Pirandello um teatro para Marta Abba, 2010. Coordena o Laboratório de Criação e Investigação da Cena Contemporânea, e o projeto de pesquisa Pirandello Contemporâneo (www.pirandellocontemporaneo.uff.br).
} 
Representamos tão completamente na vida que, para fazer teatro,

bastaria cessar a representação.

- Jerzy Grotowski

A citação em epígrafe deixa muito clara a ideia de Grotowski quanto à arte teatral, tanto em relação à função do teatro quanto em relação à função do ator. O último período de seu percurso artístico é apontado, primeiro por Peter Brook e, em seguida, multiplicado pelos estudiosos de sua obra, como a consagração da arte teatral como veículo; veículo para o artista alcançar outra potência, outra cena, muito além das representações cotidianas, muito além das representações ficcionais, imanente à própria vida interior do performer. Como declara o mestre pedagogo, foi seu interesse pelo ser humano que o levou ao teatro e, mesmo na fase dos espetáculos, eram os ensaios a coisa mais importante: "os ensaios sempre foram a grande aventura", dirá Grotowski em depoimento no vídeo Cinque sensi del teatro, produzido pelo Workcenter em 1992.

A arte teatral seria então a via privilegiada de acesso do homem ao seu interior, àquilo que impulsionaria o performer a ter um encontro real com ele mesmo, sem medos, sem mentiras, sem se esconder, sem se impor. Assim, questionará Grotowski: o que é um homem? Nossa civilização - e claro que Grotowski está falando da ocidental - está doente de esquizofrenia, pois se constitui na fratura entre o corpo e a alma, entre pensamento e gesto etc. O performer, ao contrário, dirá o mestre, é inteiro, é completo em si mesmo: "o homem inteiro, isto é que não se esconde, que vive assim como é, não é um qualquer". Zbigniew Osinski, um dos maiores estudiosos do mestre polaco, assim referenciado por Franco Ruffini, percebe em Grotowski uma nítida aspiração em obter uma visão do homem: "um ser pleno de sentido, cuja finalidade é jogar fora os "véus" e assim, encontrar o "eu" real e a completa identidade consigo mesmo, isto é, com o próprio ser divino interior." (2004, p. 297) Por tudo isso, completa Osinski, no pensamento de Grotowski não haverá espaço para se "interpretar papéis", como não haverá espaço para conceitos como "teatro," "encenação," "ator", "espectador":

Existem palavras que estão mortas, mesmo que ainda as utilizemos. Algumas estão mortas não porque agora é necessário substituílas por outras, mas porque está morto aquilo que 
significavam. Pelo menos é assim para muitos de nós. [...] Mas então, o que é necessário? O que é vivo? A aventura e o encontro, mas não qualquer um. (GROTOWSKI apud OSINSKI, 2004, p. 296. Tradução nossa)

Esses conceitos, condenados por Grotowski, imediatamente nos remetem a tudo de "impuro", de "contaminado", de "ficcional" que é inerente ao teatro. Toda essa estrutura da ordem da representação, dos simulacros, dos véus, das máscaras e aparências, será obviamente questionada por este pensador que sempre buscou a "transparência", a "pureza", a "essencialidade" não contaminada pelo artifício. Em seu lugar, Grotowski deseja a aventura viva do ensaio, o encontro real, completo, o gesto não automatizado. Como dirá em O Performer, o performer é um homem de ação (do impulso), do fazer. Contrariamente, o homem da representação pertence a outra ordem, tudo nele responde a algo anterior à ação, à teoria, aos conceitos. Afinal, este homem que representa é um homem fraturado, dividido entre corpo e mente, tudo que faz já é cópia, é desencontro, pois buscando imitar, buscando criar uma vida ficcional, buscando o melhor gesto, buscando acertar, preenchendo os vazios com códigos preestabelecidos, já catalogados, esse homem da representação se perde dele mesmo para imitar um artifício, uma casca oca, sem vida, exterior a ele. As experiências práticas do Teatro Laboratório caminharam em sentido contrário a esta dilaceração dualista, de negação desta via representativa, para enfim alcançar a visão grotowskiana de um “homem límpido", pleno.

Um dos caminhos para ascender à via criativa e vir a ser este homem límpido, transparente, o Performer, é ativar, descobrindo em si mesmo, "uma corporalidade antiga à qual somos ligados por uma relação ancestral forte". Essa afirmação de Grotowski, presente no fundamental texto O Performer $(1988)^{2}$, nos instiga, pois lança mão de termos como memória e reminiscência, conceitos que buscamos compreender pela via do processo atoral. O pedagogo observa que quando ele trabalha muito perto da essência, ele tem a impressão de atualizar a memória: "quando a essência é ativada é como se potencialidades muito fortes se ativassem. A reminiscência é talvez uma destas potencialidades". Tratamos aqui de evocar a famosa imagem contida no Eu-Eu de Grotowski: o pássaro que bica e o pássaro que olha; famosa imagem do Upanishad da Árvore da vida dos dois pássaros, um ativo e o outro contemplativo. Essa imagem, que corresponde a uma dupla dimensão da vida, um duplo caminho, vertical e horizontal, é essencial para pensarmos as experiências laboratoriais do artista. Para Grotowski, a experiência do performer é sempre dupla, ele está dentro e fora do tempo, ao mesmo tempo, 
pois percorre uma terceira via que o faz escapar do dualismo dilacerante. A terceira via (para Osinski, Grotowski seria um dos artistas do século XX mais ativos nesta busca), é a totalidade que existe no Eu-Eu:

Podemos ler nos textos antigos: Nós somos dois. O pássaro que bica e o pássaro que olha. Um morrerá, um viverá. Embriagados de estar dentro do tempo, preocupados em bicar, nos esquecemos de fazer viver a parte de nós mesmos que olha. Existe então o perigo de se existir somente dentro do tempo e nulamente fora do tempo. Se sentir olhado pela outra parte de si mesmo, esta que está como que fora do tempo, dá uma outra dimensão. Existe um Eu-Eu. O segundo Eu é quase virtual; não está em nós o olhar dos outros, nem o julgamento, é como um olhar imóvel: presença silenciosa, como o sol que ilumina as coisas e é tudo. O processo de cada um pode se completar somente no contexto desta presença imóvel. Eu-Eu: na experiência a dupla não aparece separada, mas como plena, única. [...] O Eu-Eu não quer dizer estar cortado em dois, mas ser duplo. Se trata aqui de ser passivo na ação e ativo no olhar (ao contrário do habitual). Passivo quer dizer receptivo. Ativo ser presente. (GROTOWSKI, 1988)

A plenitude alcançada por essa dupla presença corresponde à experiência do ritual, vai dizer Osinski: "o ritual está ligado, sobretudo, à verticalidade, mas também possui referências horizontais, por exemplo, interpessoais e sociais". (2004, p. 300) Eugenio Barba, em A Canoa de papel (2009), assim observa o processo criativo do performer a partir da terceira via: "as técnicas extracotidianas do corpo consistem em procedimentos físicos que aparecem fundados sobre a realidade que se conhece, mas segundo uma lógica que não é imediatamente reconhecível. [...] que faz emergir o essencial das ações e distancia o corpo das técnicas cotidianas". (BARBA, 2009, p. 63) Quer dizer, os automatismos inerentes às técnicas cotidianas são substituídos, mas não há um desligamento completo da via horizontal, pois não se persegue o assombro, o corpo é crível, porém potencializado em um corpo-memória.

O simbolismo arcaico dos dois pássaros já foi observado em Mircea Eliade em 1962:

O motivo da Árvore da Vida com estes dois pássaros se pode encontrar desde a pré-história. Há muito tempo desejava escrever um artigo sobre este simbolismo arcaico. Mas por que estou assim comovido ao ouvir estes pássaros na magnólia? Qual misterioso sentido se revela sem a intervenção da minha consciência, para que a "revelação" chegasse ao mais profundo do meu ser? Lembro-me improvisadamente de alguns textos indianos, aos quais não pensava há trinta anos. Mais uma vez constato o quanto é concreta a filosofia indiana aos seus herdeiros, 
indissoluvelmente ligada às imagens e aos gestos. (Mircea ELIADE, Religione, letteratura e comunismo, apud OSINSKI, 2004, p. 301. Tradução nossa)

Neste ponto, evocamos Walter Benjamim em suas considerações sobre a memória e a reminiscência, contidas no ensaio O Narrador (1936). Benjamim vai dizer que "a memória é a mais épica de todas as faculdades" (1985, p. 210) e que a reminiscência é aquilo que se conserva na memória. Interessante notar que para Benjamin o declínio da narrativa se deu pelo romance, que encontrou seu elemento favorável no florescimento da burguesia, mas seu derradeiro final veio com o surgimento da informação, pois se a narrativa trata do saber que vem de longe, a informação "aspira a uma verificação imediata". Ora, a informação não se detém na memória, ela é avessa à contemplação, ao surpreendente, ela é instantânea, porque já vem com uma explicação plausível, anterior à experiência. Já a narrativa evita explicações: "o extraordinário e o miraculoso são narrados com a maior exatidão, mas o contexto psicológico da ação não é imposto ao leitor. Ele é livre para interpretar a história como quiser". (BENJAMIN, 1985, p. 203)

O que fica claro até aqui é a ideia de que a narrativa, avessa a explicações psicológicas, é a arte de conservar na memória a experiência, seja ela sua própria experiência ou aquela relatada por outro. A narrativa, nestes termos, é um processo de assimilação da história à própria experiência, um processo de ligação, de pertencimento, a algo que vem de longe, ancestral. E Benjamin completa afirmando que "esse processo de assimilação se dá em camadas muito profundas e exige um estado de distensão cada vez mais raro". (1985, p. 204) O que se conserva na memória é da ordem do conhecimento e aqui novamente podemos pensar no processo criativo do performer, isto é, "o homem de conhecimento," dirá Grotowski: "[...] um rebelde que deve conquistar o conhecimento; mesmo se ele não é maldito pelos outros, ele se sente diferente, como um outsider. [...] O homem de conhecimento dispõe do doing, do fazer e não de ideias ou de teorias. [...] O conhecimento é uma questão do fazer." (GROTOWSKI, 1988) E se a reminiscência, no dizer de Grotowski, é uma potência ativada pela essência, para Benjamin, a reminiscência "funda a cadeia da tradição". (1985, p. 211) Ao ativar essa potencialidade, o performer realiza "o ato total", assim definido por Grotowski:

É muito difícil explicar no que consiste o caminho em direção a este tipo de ato, de ato atoral [...]. Se vocês viram, por exemplo, "O Príncipe Constante", é possível ter uma ideia dele através do papel de Ryszard Cieslak, o Príncipe Constante; ou se viram Akropolis, isso acontece na cena do final, quando o cortejo vai em direção ao forno crematório; [...] Se o ato tem lugar, 
então o ator, isto é, o ser humano, ultrapassa o estado de incompletude ao qual nós mesmos nos condenamos na vida cotidiana. Esmorece então a divisão entre pensamento e sentimento, entre corpo e alma, entre consciente e inconsciente, entre ver e instinto, entre sexo e cérebro; o ator que faz isso alcança a inteireza. [...] Se o ator consegue cumprir este tipo de ato e isso na colisão com o texto, que mantém para nós a sua vitalidade, a reação que nasce em nós contém uma singular união daquilo que é individual e coletivo. [...] O que é coletivo, como ligado à espécie, e o que é pessoal, se conjugam no mesmo ponto, é essa uma das características fundamentais do ato. [...] Não se trata mais de atuar, eis porque é um ato. [...] Esse é o fenômeno da ação total (eis porque queríamos chamá-lo de ato total). Ele, o ator, não está mais dividido, naquele momento não existe mais pela metade. Repete a partitura e ao mesmo tempo se desvela até os limites do impossível, até aquela semente do seu ser, que chamo de arrièrre-être. O impossível é possível. (GROTOWSKI, 2010, p. 134)

A imagem do "ato total", do "homem total", se opõe ao dualismo que separa o essencial e o temporal, o coletivo do individual, o interior do exterior. São esses duplos (espontaneidade e disciplina; corpo e mente; pensamento e emoção etc.) a matéria prima do pensamento de Grotowski: o conjunction oppositorum entre espontaneidade e estrutura. São os detalhes plásticos, os pequenos gestos, resultados das experiências de cada performer, que ativam o corpo-memória, que permitem a imersão do performer nas recordações. No entanto, para ativar a memória "a totalidade do nosso ser", será preciso eliminar tudo que é excessivamente artificial ou estético, tudo aquilo que bloqueia o corpo-memória, o corpo-vida. Os detalhes improvisados, espontâneos, não podem ser apenas gestos, envolvendo braços e pernas, eles devem estar "radicados na totalidade do corpo". Afinal, como dirá Grotowski, "toda reação autêntica tem início no interior do corpo. O exterior é somente o fim desse processo". (2010, p. 172)

E aqui, novamente podemos voltar ao texto "O Narrador" no trecho em que Benjamin cita Lukács: "o sujeito só pode ultrapassar o dualismo da interioridade e da exterioridade quando percebe a unidade de toda sua vida... na corrente vital do seu passado, resumida na reminiscência..." (LUKÁCS apud BENJAMIN, 1985, p. 212) E para ficarmos com Benjamim, nos perguntamos ao lado do filósofo: "a relação entre o narrador e sua matéria - a vida humana não seria ela própria uma relação artesanal? Não seria sua tarefa trabalhar a matéria-prima da experiência - a sua e a dos outros - transformando-a num produto sólido, útil e único?" Para Benjamin, o narrador figura entre os mestres e os sábios, pois só ele pode "recorrer ao acervo 
de toda uma vida", que não é só dele, mas que inclui as lembranças de outras vidas. "O narrador é a figura na qual o justo se encontra consigo mesmo". (1985, p. 221) E aqui citamos Grotowski:

Por que nos preocupamos com arte? Para cruzar fronteiras, vencer limitações, preencher nosso vazio - para nos realizar. Não se trata de uma condição, mas de um processo através do qual o que é obscuro em nós torna-se paulatinamente claro. (GROTOWSKI apud OSINSKI, 2004, p. 323)

A ideia de uma relação artesanal, proposta por Benjamim, entre o narrador e sua matéria prima, se assemelha com os objetivos dos exercícios corporais de Grotowski pensados para os atores, nos quais se trabalha um longo caminho de seleção e de eliminação. Podemos entender, a partir de Benjamim, que os bloqueios observados por Grotowski em seus atores (não só físicos, mas principalmente de sua atitude em relação ao próprio corpo) são o resultado de um excesso de informação que impede a experiência real do performer com seu corpo, que impede o despertar do corpo-memória ou o acontecimento do corpo-experiência (termo cunhado a partir da influência benjaminiana). Então os exercícios são um caminho para superar a divisão entre "mim" e "meu corpo", dirá Grotowski. A informação, assim como o teatro que treina seus atores para o virtuosismo corporal, domestica ou adoece o corpo já que, anterior à experiência, impede que o corpo tenha a possibilidade de "viver" uma experiência viva:

O corpo não tem memória, ele é memória. O que devem fazer é desbloquear o "corpo-memória". Se começam a usar detalhes precisos nos exercícios "plásticos" e dão o comando a vocês: agora devo mudar o ritmo, agora devo mudar a sequência dos detalhes etc., não liberaram o corpo-memória. Justamente porque é um comando. Portanto é a mente que age. Mas se vocês mantêm os detalhes precisos e deixam que o corpo determine os diferentes ritmos, mudando continuamente o ritmo, mudando a ordem, [...] então quem dá os comandos? Não é a mente e nem acontece por acaso, isso está em relação com a nossa vida. (GROTOWSKI, 2010, p. 173)

O corpo comandado, bem-informado, seria um corpo pobre de experiências, pois todo o gesto acionado vem precedido de uma explicação, quando o que se deseja no treinamento do ator, na arte como veículo, é evitar o comentário, interromper o automatismo e permitir o despertar do corpo-memória, o corpo-vida, esvaziando o ator dos excessos de informação, permitindo a fluidez, o ato. E aqui citamos Benjamim: "o narrador é o homem que poderia deixar a luz tênue de sua narração consumir completamente a mecha de sua vida". (1985, p. 221) Assim como o narrador de Benjamin, o Performer (assim, com letra maiúscula) de Grotowski sabe rememorar, ele é um "fazedor de pontes" e não tem medo de sua morte. 


\section{Notas}

10 vídeo integra o acervo pessoal da autora.

2 Conferência pronunciada por Grotowski e publicada pela Art-Press em 1987. Texto original em francês traduzido por Celina Sodré (sem publicação).

\section{Referências}

BARBA, Eugenio. A Canoa de Papel: Tratado de Antropologia Teatral. Brasília: Ed. Dulcina, 2009.

BENJAMIN, Walter. O Narrador. In: Magia e técnica, arte e política: ensaios sobre literatura e história da cultura. Obras escolhidas, vol. 1. São Paulo: Editora Brasiliense, 1985.

DE MARINIS, Marco. Nova Teatralogia e Performance Studies: Questões para um diálogo. Repertório: Teatro \& Dança, Salvador (UFBA), v. 13, n. 15, 2010.

GROTOWSKY, Jerzy. Performer. In: Centro di lavoro di Jerzy Grotowski - Workcenter of Jerzy Grotowski. Pontedera: Centro per la Sperimentazione e la Ricerca Teatral, 1988

GROTOWSKY, Jerzy. Jersy Grotowski. Teatro e Ritual. In: O Teatro Laboratório de Jersy Grotowski 1959-1969. São Paulo: Perspectiva, 2010

OSINSKI, Zbigniew. Grotowski e la Gnosi. Teatro e storia, XVIII, 2004. 